\title{
COMMENTARY
}

\section{Nurses and ventilators}

\author{
Amal Jubran ${ }^{* 1,2}$ \\ See related research by Rose et al., http://ccforum.com/content/15/6/R295
}

\begin{abstract}
In the previous issue of Critical Care, Rose and colleagues report the results of a survey on the frequency with which ICU nurses are involved in decision-making in ventilator management. About 63 to $88 \%$ of the decisions were made by nurses in collaboration with physicians, and as much as $68 \%$ of ventilator adjustments were performed by nurses independent of physicians. Nurse involvement in decision-making was twice as likely in ICUs that use weaning protocols. The ICU nurse performs many roles, the most important being the continuous observation of a patient. The diversion of a nurse's attention from constant vigilance by performing tasks of no benefit, such as the use of weaning protocols, would be a most unfortunate turn of events.
\end{abstract}

One of the major motivations behind the introduction of ICUs was to have nurses in immediate attendance so that patients could be constantly observed. Through vigilance, a nurse is able to detect early changes in a patient's condition, and, by alerting other team members, the nurse can subvert a disaster in the making.

In Australia and New Zealand, ICU nurses are actively involved in making decisions about ventilator management and frequently adjust ventilator settings without input from physicians. In a sense, they assume many of the responsibilities borne by respiratory therapists in the United States. To determine the practice in other countries, Rose and colleagues conducted a multicenter self-administered survey of nurse managers of ICUs in eight European countries [1]. About 63 to 88\% of decisions regarding ventilator management were made by nurses in collaboration with physicians. Moreover, nurses perfomed 40 to $68 \%$ of ventilator adjustments independent

*Correspondence: ajubran@lumc.edu

'Division of Pulmonary and Critical Care Medicine, Edward Hines Jr Veterans Affairs Hospital, 111N, $5^{\text {th }}$ Avenue and Roosevelt Road, Hines, IL 60141, USA

Full list of author information is available at the end of the article of physicians. Regression analysis showed that collaborative decisions were more likely in ICUs that have a nurseto-patient ratio of $1: 1$ and have weaning protocols in place.

The major strength of the study is the large number of ICUs $(n=586)$ surveyed by Rose and colleagues [1]. The inclusion of data from several countries provides new insight into the involvement of ICU nurses in ventilator management.

The degree of collaboration between physicians and nurses was not specified. Respondents were simply asked to select a category (nurse, physicians, or nurses and physicians) that best reflected their involvement in ventilator decisions. The word 'collaboration', however, has no universal meaning and can mean different things to different people. For one person, collaboration might mean nothing more than a nurse informing a physician that a patient's condition has improved. For another, collaboration may mean that the nurse makes an explicit recommendation to decrease pressure support by $7 \mathrm{cmH}_{2} \mathrm{O}$.

The respondents in the survey were nurse managers. This group is not representative of the average ICU nurse, and may overestimate the independence of nurses in decision-making. To avoid the problem of self-report bias, which is inherent in surveys, ethnographers directly observe human events in the context in which they occur [2]. An ethnographer would be able to capture what it is that a nurse actually does - rather than what nurses think they do.

Rose and colleagues focused on weaning, and noted that decision-making by nurses in this area has been linked to the introduction of weaning protocols [1]. The survey reveals that nurse involvement in decision-making was twice as likely (odds ratio 1.8) in ICUs that use weaning protocols. Randomized controlled trials, in my opinion, have shown weaning protocols to be without benefit [3-5].

Survey respondents reported that they frequently titrate pressure support and ventilator tidal volume and frequency without consulting a physician. This is not the practice of nurses or respiratory therapists in any ICU in which I have worked - nor of any ICU that I have visited. Of note, $85 \%$ of the surveyed ICUs contained surgical 
patients. Ventilating postoperative patients is relatively easy - in these patients, titration of ventilator settings can be rather formulaic. However, in ICU patients with coexisting illnesses, such as those with acute respiratory distress syndrome or chronic obstructive pulmonary disease, the response to mechanical ventilation is frequently unpredictable [6]. Managing such patients requires a clinician who has a sophisticated understanding of physiology and can recognize unexpected responses that follow ventilator adjustments. For example, improper adjustment of pressure support in a patient with chronic obstructive pulmonary disease can lead to Cheyne-Stokes breathing; can induce recruitment of abdominal muscles causing the patient to buck the ventilator; or can escalate the amount of ineffective triggering $[7,8]$.

The part played by nurses in the care of patients is complementary to - and not subsidiary to - the role of physicians. The nurse is constantly present at the patient's bedside, and an experienced nurse can sense problems in the making (the sixth sense of an expert) and institute steps to avert a catastrophe. Nurses help patients cope with the most embarrassing and demeaning consequences of a critical illness. Such intimate interaction means that the patient-nurse bond is more personal than the bond between patients and doctors. It would be most unfortunate if nurses were to become distracted from these vital and unique skills by diverting their attention to tasks of no benefit, such as the use of ventilator protocols.

We owe a debt of gratitude to Dr Rose and her colleagues for informing the critical care community of how nurses are currently spending their time when caring for critically ill patients. The impact of the expanding role of nurses in ventilator management on patients' well-being remains unknown.

\section{Author details}

'Division of Pulmonary and Critical Care Medicine, Edward Hines Jr Veterans Affairs Hospital, 111N, $5^{\text {th }}$ Avenue and Roosevelt Road, Hines, IL 60141, USA. ¿2Loyola University Medical Center, Division of Pulmonary and Critical Care Medicine, 2160 South 1st Avenue, Maywood, IL 60153, USA.

\section{Competing interests}

The author declares that they have no competing interests.

Published: 27 February 2012

\section{References}

1. Rose L, Blackwood B, Egerod I, Haugdahl HS, Hofhuis J, Isfort M, Kydonaki K, Schubert M, Sperlinga R, Spronk P, Storli S, McAuley DF, Schultz MJ: Decisional responsibility for mechanical ventilation and weaning: an international study. Crit Care 2011, 15:R295.

2. Tanenbaum SJ: Knowing and acting in medical practice: the epistemological politics of outcomes research. J Health Polit Policy Law 1994, 19:27-44.

3. Krishnan JA, Moore D, Robeson C, Rand CS, Fessler HE: A prospective, controlled trial of a protocol-based strategy to discontinue mechanical ventilation. Am J Respir Crit Care Med 2004, 169:673-678.

4. Randolph AG, Wypij D, Venkataraman ST, Hanson JH, Gedeit RG, Meert KL, Luckett PM, Forbes P, Lilley M, Thompson J, Cheifetz IM, Hibberd P, Wetzel R, Cox PN, Arnold JH: Effect of mechanical ventilator weaning protocols on respiratory outcomes in infants and children: a randomized controlled trial. JAMA 2002, 288:2561-2568.

5. Namen AM, Ely EW, Tatter SB, Case LD, Lucia MA, Smith A, Landry S, Wilson JA, Glazier SS, Branch CL, Kelly DL, Bowton DL, Haponik EF: Predictors of successful extubation in neurosurgical patients. Am J Respir Crit Care Med 2001, 163(3 Pt 1):658-664.

6 Tobin MJ, Laghi F, Jubran A: Ventilatory failure, ventilator support and ventilator weaning. Compr Physiol 2012, in press.

7. Jubran A, Van de Graaff WB, Tobin MJ: Variability of patient-ventilator interaction with pressure-support ventilation in patients with COPD. Am 」 Respir Crit Care Med 1995, 152:129-136.

8. Leung P, Jubran A, Tobin MJ: Comparison of assisted ventilator modes on triggering, patient effort, and dyspnea. Am J Respir Crit Care Med 1997, 155:1940-1948.

doi:10.1186/cc11186

Cite this article as: Jubran A: Nurses and ventilators. Critical Care 2012, 16:115. 